\title{
Loss of HCN from the Pyrazine Molecular Ion: A Theoretical Study
}

\author{
Sun Hwa Jung, Min Kyoung Yim, and Joong Chul Choe* \\ Department of Chemistry, Dongguk University-Seoul, Seoul 100-715, Korea. *E-mail: jcchoe@dongguk.edu \\ Received April 15, 2011, Accepted May 23, 2011

\begin{abstract}
The potential energy surface (PES) for the loss of $\mathrm{HCN}$ or $\mathrm{HNC}$ from the pyrazine molecular ion was determined based on quantum chemical calculations using the G3//B3LYP method. Four possible dissociation pathways to form four $\mathrm{C}_{3} \mathrm{H}_{3} \mathrm{~N}^{+}$isomers were examined. A Rice-Ramsperger-Kassel-Marcus quasi-equilibrium theory model calculation was performed to predict the dissociation rate constant and the product branching ratio on the basis of the obtained PES. The resultant rate constant for the HCN loss agreed with the previous experimental result. The kinetic analysis predicted that the formation of $\mathrm{CH}=\mathrm{CHN} \equiv \mathrm{CH}^{+\bullet}+\mathrm{HCN}$ was predominant, which occurred by three consecutive steps, a $\mathrm{C}-\mathrm{C}$ bond cleavage to form a linear intermediate, a rearrangement to form an $\mathrm{H}$-bridged intermediate, and elimination of $\mathrm{HCN}$.
\end{abstract}

Key Words : Potential energy surface, G3//B3LYP calculation, RRKM calculation, Kinetics, Reaction pathway

\section{Introduction}

Understanding heterocyclic chemistry is important in several disciplines, such as organic and physical chemistry, biochemistry, pharmacy, pharmacology, medicinal chemistry, material science, etc. Mass spectrometry has been used mostly to confirm or deduce structures of heterocyclic compounds and their fragments. ${ }^{1}$ Generally, the mass spectrum of a polyatomic molecule contains many fragment peaks, indicating that ion dissociation occurs by several competitive and consecutive reactions. Various experimental techniques have been developed to understand ionic dissociation kinetics, dynamics, and mechanisms, which include photoelectron-photoion coincidence (PEPICO) spectroscopy, timeresolved photodissociation with ion cyclotron resonance mass spectrometry, and photodissociation mass-analyzed ion kinetic energy spectrometry. ${ }^{2}$ Theoretical studies based on quantum chemical calculations can provide insights into ionic dissociation kinetics and mechanisms. For example, the dissociations of several ionic benzene derivatives were studied theoretically in this laboratory. ${ }^{3-12}$ Theoretical dissociation mechanisms of some hetero-aromatic systems have been suggested with the aid of quantum chemical calculations. ${ }^{13-18}$

Recently, the dissociation of the pyridine molecular ion has been investigated by theoretical means. ${ }^{16}$ The kinetic analysis based on the calculated potential energy surface (PES) showed that the fragment ions, $\mathrm{C}_{4} \mathrm{H}_{4}{ }^{+}$, produced by the loss of HCN were a mixture of methylenecyclopropene and vinylacetylene radical cations, similar to the formation of $\mathrm{C}_{4} \mathrm{H}_{4}{ }^{+}$from the benzene molecular ion. The branching ratio predicted from the kinetic analysis showed a dramatic dependency on the ion internal energy. The formation of the vinylacetylene radical cation was dominant at energies corresponding to metastable dissociation, and its relative abundance decreased as the energy increased. Interestingly, the common initial step for both the dissociation channels was an isomerization by a 1,2-H shift.

In this work, the dissociation of the pyrazine (1,4-diazine) molecular ion (1, Figure 1) was investigated as a first attempt to understand the dissociation kinetics and mechanisms of three diazine $\left(\mathrm{C}_{4} \mathrm{H}_{4} \mathrm{~N}_{2}{ }^{+\bullet}\right)$ isomers. The structure and reactions of $\mathbf{1}$ have been studied using experimental and theoretical means. ${ }^{17,19-22}$ In the $70-\mathrm{eV}$ electron ionization mass spectrum $^{23}$ and collision-induced dissociation spectrum ${ }^{17}$ of pyrazine, the $m / z 53$ and 26 peaks are major fragment peaks

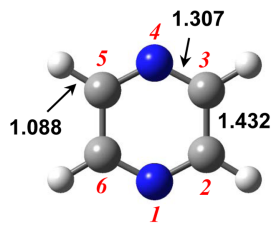

Pyrazine $^{+\bullet}\left(1, D_{2 \mathrm{~h}}\right)$
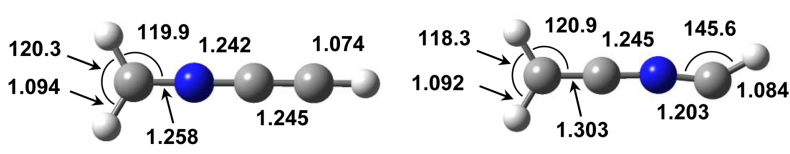

$$
\mathrm{CH}_{2}=\mathrm{N}=\mathrm{C}=\mathrm{CH}^{+\bullet}\left(C_{2 \mathrm{v}}\right)
$$

$(0.0)$

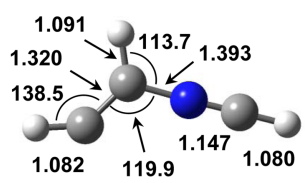

(E) $-\mathrm{CH}=\mathrm{CHN} \equiv \mathrm{CH}^{+\bullet}\left(C_{\mathrm{s}}\right)$

(7.8)

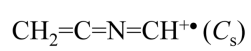

(7.4)

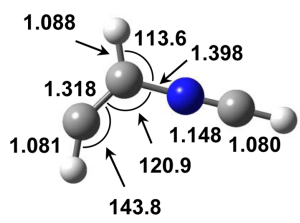

$(Z)-\mathrm{CH}=\mathrm{CHN} \equiv \mathrm{CH}^{+\bullet}\left(C_{\mathrm{s}}\right)$

(13.1)
Figure 1. Geometric structures of $\mathbf{1}$ and $\mathrm{C}_{3} \mathrm{H}_{3} \mathrm{~N}^{+}$isomers optimized by the B3LYP/6-31G(d) calculations. The numbers are the bond lengths in $\AA$ and the angles in degree. The values in parentheses are relative energies of $\mathrm{C}_{3} \mathrm{H}_{3} \mathrm{~N}^{+} \bullet$ isomers in $\mathrm{kJ} \mathrm{mol}^{-1}$, calculated by the G3//B3LYP method. 
that correspond to fragment ions formed by the loss of $\mathrm{HCN}$ and $2 \mathrm{HCN}$ from 1, respectively. The breakdown curves for the dissociation of $\mathbf{1}$ were obtained using the PEPICO method and were fitted by a Rice-Ramsperger-Kassel-Marcus (RRKM) model calculation. ${ }^{21}$ However, the detailed dissociation mechanism has not been proposed. The PES for the formation of several $\mathrm{C}_{3} \mathrm{H}_{3} \mathrm{~N}^{+\bullet}$ isomers by the loss of $\mathrm{HCN}$ or $\mathrm{HNC}$ was examined using quantum chemical calculations. The isomerization and dissociation kinetics were discussed on the basis of the PES.

\section{Computational Methods}

The molecular orbital calculations were performed using the Gaussian 09 suite of programs. ${ }^{24}$ The geometries of the stationary points were optimized at the unrestricted B3LYP level of the density functional theory (DFT) using the 6$31 \mathrm{G}(\mathrm{d})$ basis set. The transition state (TS) geometries that connected the stationary points were examined and checked by calculating the intrinsic reaction coordinates at the same level. For better accuracy of the energies, G3 theory calculations using the B3LYP density functional method (G3// B3LYP) $)^{25}$ were performed.

The RRKM expression was used to calculate the rate constant for the unimolecular reaction steps that were involved in the selected reaction pathways because the RRKM formula for the microcanonical ensemble was mathematically equivalent to the formula in the statistical quasi-equilibrium theory that was developed for the ionic dissociations: ${ }^{2}$

$$
k(E)=\frac{\sigma N^{*}\left(E-E_{0}\right)}{h \rho(E)}
$$

In this equation, $E$ is the internal energy of the reactant, $E_{0}$ is the critical energy of the reaction, $N^{*}$ is the sum of the TS states, $\rho$ is the density of the reactant states, $\sigma$ is the reaction path degeneracy, and $h$ is Planck's constant. $N^{*}$ and $\rho$ were evaluated through a direct count of the states using the Beyer-Swinehart algorithm. ${ }^{26}$ Each normal mode of vibration was treated as a harmonic oscillator. The vibrational frequencies that were obtained from the B3LYP/6-31G(d) calculations were scaled down by a factor of $0.9614 .{ }^{27}$ The rate constants were calculated at $0 \mathrm{~K}$, which means that rotational effects were ignored.

\section{Results and Discussion}

1 possesses four chemically equivalent carbons and two chemically equivalent nitrogens, and it belongs to the $D_{2 \mathrm{~h}}$ group (Figure 1). There are four possible initial isomerization steps to eliminate $\mathrm{HCN}$ or HNC from 1. Two of those steps occur by a direct cleavage of either the $\mathrm{C} 2-\mathrm{C} 3$ bond (channel 1, see Figure 1 for numbering) or the N1-C2 bond (channel 2). The other two occur by a hydrogen shift either from $\mathrm{C} 2$ to $\mathrm{C} 3$ (channel 3) or from C2 to N1 (channel 4). All of these possible pathways were examined in this work, which eventually formed several products as follows;

$$
\begin{aligned}
& \mathrm{C}_{4} \mathrm{H}_{4} \mathrm{~N}_{2}{ }^{+\bullet}(\mathbf{1}) \rightarrow \mathrm{CH}=\mathrm{CHN} \equiv \mathrm{CH}^{+\bullet}+\mathrm{HCN}, \quad \text { channel } 1 \text { (2) } \\
& \mathrm{C}_{4} \mathrm{H}_{4} \mathrm{~N}_{2}{ }^{+\bullet}(\mathbf{1}) \rightarrow \mathrm{CH}_{2}=\mathrm{N}=\mathrm{C}=\mathrm{CH}^{+\bullet}+\mathrm{HNC} \text {, channel } 2 \text { (3) } \\
& \mathrm{C}_{4} \mathrm{H}_{4} \mathrm{~N}_{2}^{+}{ }^{+}(\mathbf{1}) \rightarrow \mathrm{CH}_{2}=\mathrm{C}=\mathrm{N}=\mathrm{CH}^{+\bullet}+\mathrm{HCN} \text {, channel } 3 \text { (4) } \\
& \mathrm{C}_{4} \mathrm{H}_{4} \mathrm{~N}_{2}^{+}{ }^{+}(\mathbf{1}) \rightarrow \mathrm{CH}_{2}=\mathrm{N}=\mathrm{C}=\mathrm{CH}^{+\bullet}+\mathrm{HCN} \text {, channel } 4 \text { (5) }
\end{aligned}
$$

Both of the $E$ and $Z$ isomers of $\mathrm{CH}=\mathrm{CHN} \equiv \mathrm{CH}^{+\bullet}$ can be formed in channel 1 . The optimized geometries of the four possible product $\mathrm{C}_{3} \mathrm{H}_{3} \mathrm{~N}^{+}$ions are shown in Figure 1 with their calculated relative energies. $\mathrm{CH}_{2}=\mathrm{N}=\mathrm{C}=\mathrm{CH}^{+\bullet}$ was the most stable $\mathrm{C}_{3} \mathrm{H}_{3} \mathrm{~N}^{+\bullet}$ isomer.

Formation of $\mathbf{C H}=\mathbf{C H N} \equiv \mathrm{CH}^{+\bullet}+\mathbf{H C N}$ (channel 1). By increasing the $\mathrm{C} 2-\mathrm{C} 3$ bond distance of $\mathbf{1}$, an opened isomer cis-2 is formed (Figure 2). The PES obtained with the G3// B3LYP calculation is shown in Figure 3. As the N1-C6 bond distance increases, the HCN moiety moves toward the hydrogen on $\mathrm{C} 3$ to form an $\mathrm{H}$-bridged isomer 3. The TS for this step lies highest in the lowest energy reaction pathway in channel 1 . The final dissociation step to $(E)$ $\mathrm{CH}=\mathrm{CHN} \equiv \mathrm{CH}^{+\bullet}+\mathrm{HCN}$ has no reverse barrier. The overall critical energy of channel $1\left(266 \mathrm{~kJ} \mathrm{~mol}^{-1}\right)$ was the lowest among the dissociation channels investigated in this work. On the other hand, cis-2 can undergo a cis-trans isomerization around the C5-C6 bond to form trans-2. We tried but failed to optimize a TS connecting cis- and trans-2 (TS cis-2 $\rightarrow$ trans-2) with the B3LYP method. Trans-2 can lose $\mathrm{HCN}$ through another H-bridged isomer 4 to form (Z)$\mathrm{CH}=\mathrm{CHN} \equiv \mathrm{CH}^{+\bullet}$ which was $5 \mathrm{~kJ} \mathrm{~mol}^{-1}$ less stable than the $E$ isomer. Two ion-molecule complexes, not presented in Figure 3, were found as minima between trans-2 and 4. Their presence does not affect the dissociation kinetics because the barriers connecting the two ion-molecule complexes and 4 were negligible. $\mathbf{3}$ and $\mathbf{4}$ are rapidly interconvertible before dissociation.
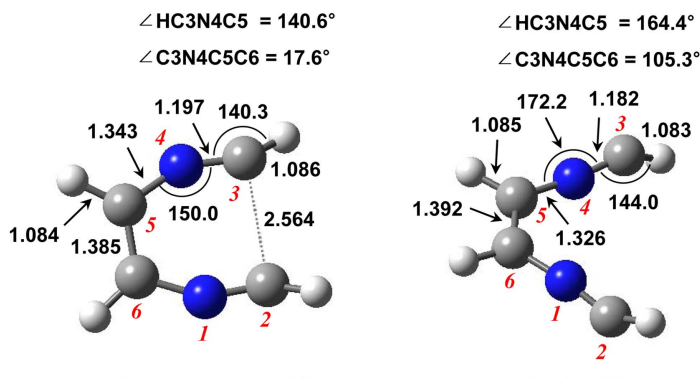

TS $1 \rightarrow$ cis-2 $\left(C_{2}\right)$

$\operatorname{cis-2}\left(C_{2}\right)$

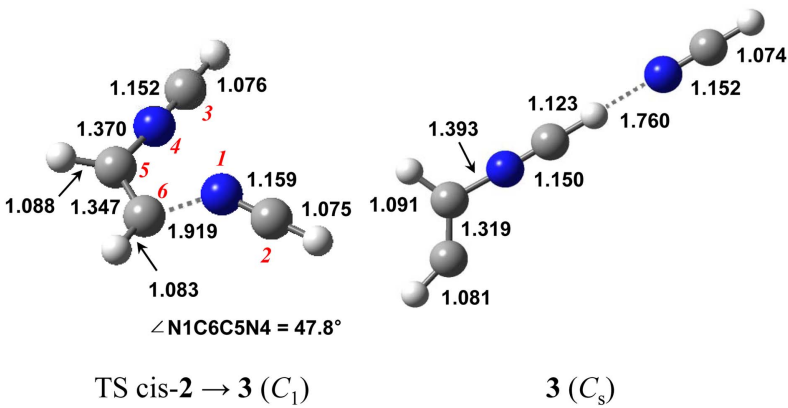

Figure 2. Geometric structures of selected $\mathrm{C}_{4} \mathrm{H}_{4} \mathrm{~N}_{2}{ }^{+}$isomers optimized by the B3LYP/6-31G(d) calculations. The numbers are the bond lengths in $\AA$ and the angles in degree. 


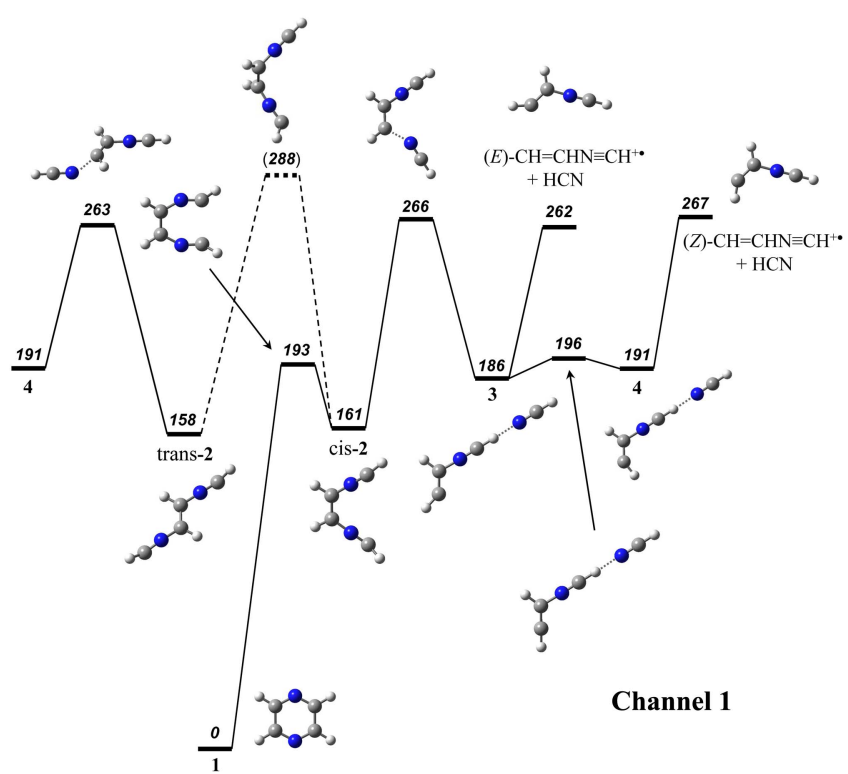

Figure 3. Potential energy diagram for the formation of $\mathrm{CH}=\mathrm{CHN} \equiv \mathrm{CH}^{+\bullet}+\mathrm{HCN}$ (channel 1), which was derived from the G3//B3LYP calculations. The energies are presented in $\mathrm{kJ} \mathrm{mol}^{-1}$. The calculated total energy of $\mathbf{1}$ was -263.7925045 hartrees. TS cis-2 $\rightarrow$ trans-2 was not optimized by the G3//B3LYP calculation but optimized by the G3 calculation. Its energy was estimated from the G3 calculation.

TS cis-2 $\rightarrow$ trans-2 was optimized in the HF/6-31G(d) calculation. Because G3 calculations ${ }^{28}$ are based on geometries optimized with the HF method, the energies of cis-2, TS cis-2 $\rightarrow$ trans-2, and trans-2 were successfully calculated with the G3 method. Their relative energies were 0 , 127 , and $0 \mathrm{~kJ} \mathrm{~mol}^{-1}$, respectively. Therefore, it is likely that TS cis-2 $\rightarrow$ trans-2 lies at about $288 \mathrm{~kJ} \mathrm{~mol}^{-1}$, which is $22 \mathrm{~kJ}$ mol $^{-1}$ higher than TS $c i s-\mathbf{2} \rightarrow \mathbf{3}$, in the PES constructed with the G3//B3LYP method. In addition, TS cis-2 $\rightarrow$ trans-2 was tighter than TS cis-2 $\rightarrow \mathbf{3}$. Accordingly, it is predicted that

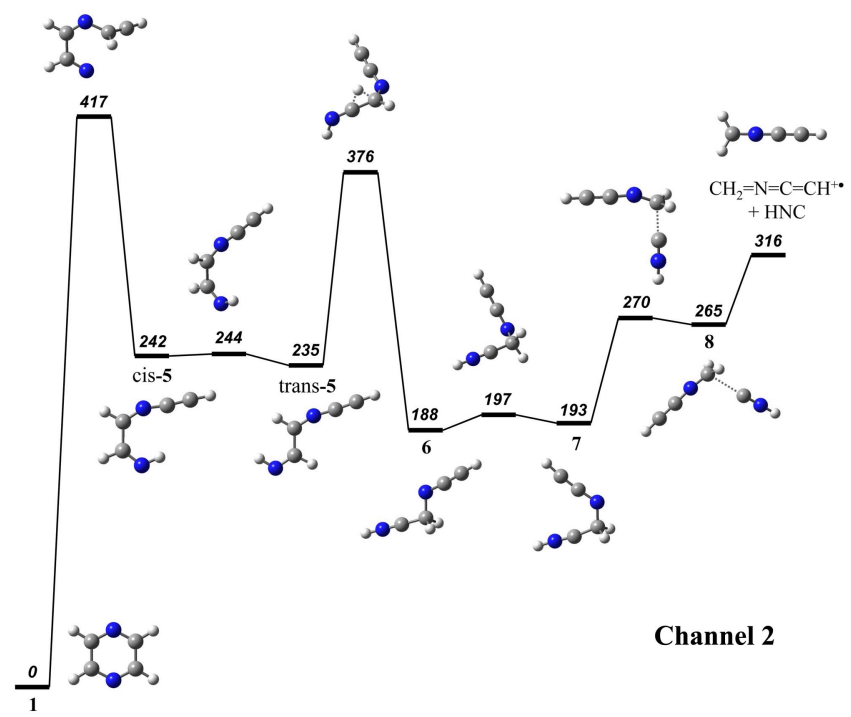

Figure 4. Potential energy diagram for the formation of $\mathrm{CH}_{2}=\mathrm{N}=\mathrm{C}=\mathrm{CH}^{+\bullet}+\mathrm{HNC}$ (channel 2), which was derived from the G3//B3LYP calculations. The energies are presented in $\mathrm{kJ} \mathrm{mol}^{-1}$.

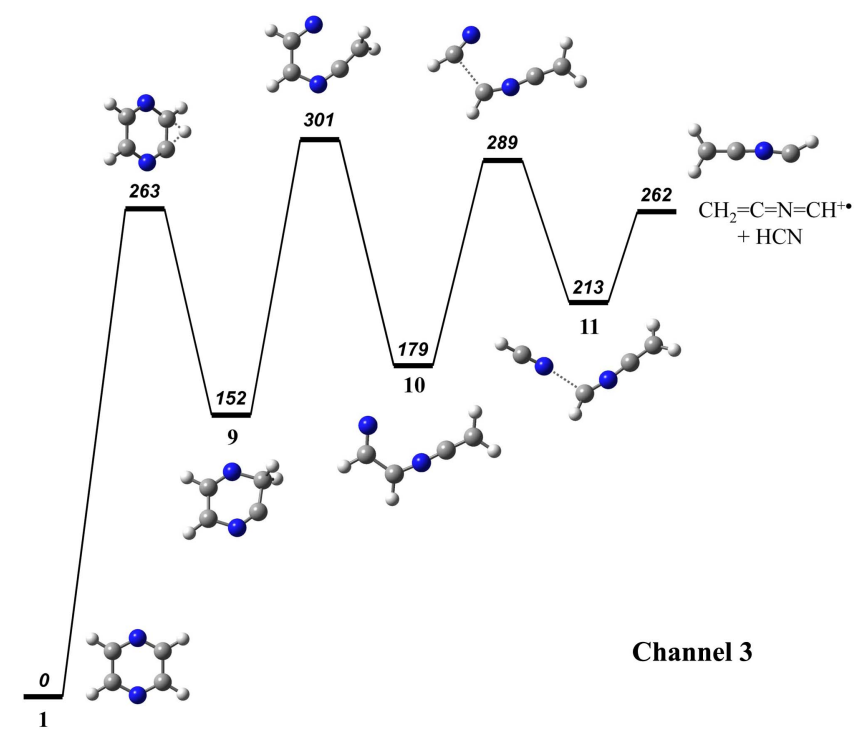

Figure 5. Potential energy diagram for the formation of $\mathrm{CH}_{2}=\mathrm{C}=\mathrm{N}=\mathrm{CH}^{+\bullet}+\mathrm{HCN}$ (channel 3), which was derived from the $\mathrm{G} 3 / / \mathrm{B} 3 \mathrm{LYP}$ calculations. The energies are presented in $\mathrm{kJ} \mathrm{mol}^{-1}$.

the isomerization cis-2 $\rightarrow$ trans-2 is much less favored than the isomerization $c i s-\mathbf{2} \rightarrow \mathbf{3}$ both energetically and entropically. ${ }^{29}$

Formation of $\mathrm{CH}_{2}=\mathrm{N}=\mathrm{C}=\mathrm{CH}^{+\bullet}+\mathrm{HNC}$ (channel 2). As the $\mathrm{N} 1-\mathrm{C} 2$ bond distance of $\mathbf{1}$ increases, the $\mathrm{H}$ on $\mathrm{C} 3$ shifts to N1 to form an opened isomer cis-5 (Figure 4). The TS for this step lies highest in channel 2. After a cis-trans isomerization, the $\mathrm{H}$ on $\mathrm{C} 6$ shifts to $\mathrm{C} 5$ to form isomer $\mathbf{6}$. A rotation around the $\mathrm{N} 4-\mathrm{C} 5$ bond forms isomer 7 . By increasing the C5-C6 bond distance of 7, an ion-molecule complex 8 is formed. Further increasing the $\mathrm{C} 5-\mathrm{C} 6$ distance eliminates $\mathrm{HNC}$ to form $\mathrm{CH}_{2}=\mathrm{N}=\mathrm{C}=\mathrm{CH}^{+}$. The overall critical energy $\left(417 \mathrm{~kJ} \mathrm{~mol}^{-1}\right)$ of the channel is much higher than that of channel 1. Therefore, it is predicted that the formation of $\mathrm{CH}_{2}=\mathrm{N}=\mathrm{C}=\mathrm{CH}^{+\bullet}+\mathrm{HNC}$ hardly occurs.

Formation of $\mathrm{CH}_{2}=\mathrm{C}=\mathrm{N}=\mathrm{CH}^{+\bullet}+\mathrm{HCN}$ (channel 3). The $\mathrm{H}$ on $\mathrm{C} 2$ shifts to $\mathrm{C} 3$ to form a distorted cyclic isomer 9 (Figure 5). By increasing the $\mathrm{C} 3-\mathrm{N} 4$ bond distance, an opened isomer $\mathbf{1 0}$ is formed. The barrier for this step lies highest in channel 3. As the HCN moiety moves further from the other part of 10, an ion-molecule complex $\mathbf{1 1}$ is formed. The final dissociation step has no reverse barrier.

Formation of $\mathbf{C H}_{2}=\mathbf{N}=\mathbf{C}=\mathbf{C H}^{+\bullet}+\mathbf{H C N}$ (channel 4). The $\mathrm{H}$ on $\mathrm{C} 2$ consecutively shifts to $\mathrm{N} 1$ and $\mathrm{C} 6$ to form a distorted cyclic isomer $\mathbf{1 3}$ (Figure 6). The TS for the second step lies highest in channel 4. By increasing the $\mathrm{C} 5-\mathrm{C} 6$ bond distance, an opened isomer $\mathbf{1 4}$ is formed. The HCN moiety is eliminated to form $\mathrm{CH}_{2}=\mathrm{N}=\mathrm{C}=\mathrm{CH}^{+\bullet}$ via an ion-molecule complex 15.

Dissociation Kinetics. The calculated overall critical energies of channels $1-4$ are 266, 417, 301, and $327 \mathrm{~kJ} \mathrm{~mol}^{-1}$, respectively. Considering these overall critical energies, channel 1 is the most favorable, even though channel 4 is the thermodynamically most favorable when only considering the endoergicity. A kinetic analysis was performed to predict 


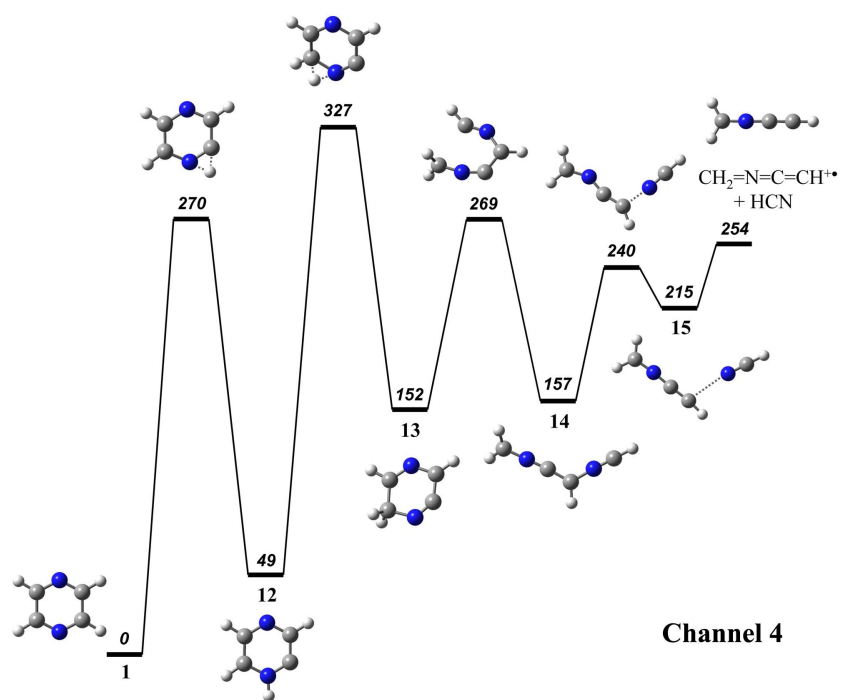

Figure 6. Potential energy diagram for the formation of $\mathrm{CH}_{2}=\mathrm{N}=\mathrm{C}=\mathrm{CH}^{+\bullet}+\mathrm{HCN}$ (channel 4), which was derived from the $\mathrm{G} 3 / / \mathrm{B} 3 \mathrm{LYP}$ calculations. The energies are presented in $\mathrm{kJ} \mathrm{mol}^{-1}$.

the rate constant for the $\mathrm{HCN}$ loss, $k_{\mathrm{HCN}}$, and product branching ratio. Channel 2 was ignored in the kinetic analysis because its occurrence was highly improbable, due to its much higher overall critical energy compared to the others. The rate equations for the minima in channels 1,3 , and 4 were set up, which consisted of individual rate constants for the forward and reverse isomerization and dissociation steps. The pathway via trans-2 in channel 1 was not included because TS cis-2 $\rightarrow$ trans-2 was not optimized. The contribution of this pathway would be small because the cis-trans isomerization would be far less favored than the isomerization $c i s-\mathbf{2} \rightarrow \mathbf{3}$, as described above. ${ }^{29}$ The MATLAB program was used to numerically solve the coupled differential equations. The solution provided the time dependence of the concentrations of $\mathbf{1}$, the intermediates, and the products at a specific ion internal energy. $k_{\mathrm{HCN}}$ was obtained by fitting an exponential law to the sum of the time dependencies of the concentrations of $\mathbf{1}$ and all the intermediates. The relative abundances of the products in channel 1, 3, and 4 were obtained from the time dependencies of their concentrations. This procedure was repeated for a range of the internal energy values.

The rate constants for the individual reaction steps were calculated using the RRKM formalism of equation (1) and used for obtaining $k_{\mathrm{HCN}}$. The critical energies that were calculated with the G3//B3LYP method were used. The reaction path degeneracies ( $\sigma$ 's) were assumed from the optimized structures. $\sigma$ of 4 was used for both the isomerizations $\mathbf{1} \rightarrow$ cis-2 and cis-2 $\rightarrow \mathbf{3}, \sigma$ of 2 for $\mathbf{3} \rightarrow$ cis-2, and $\sigma$ of 1 for the other steps in channel 1 , which is the most important channel (see below). All the final dissociation steps in channels 1, 3, and 4 occurred without reverse barriers. Because such "loose" TSs could not be located, activation entropy $\left(\Delta S^{*}\right)^{2}$ was used in calculations of rate constants of the final dissociation steps. Generally, $\Delta S^{t}$ has a positive value for a loose TS. For the dissociation steps, the

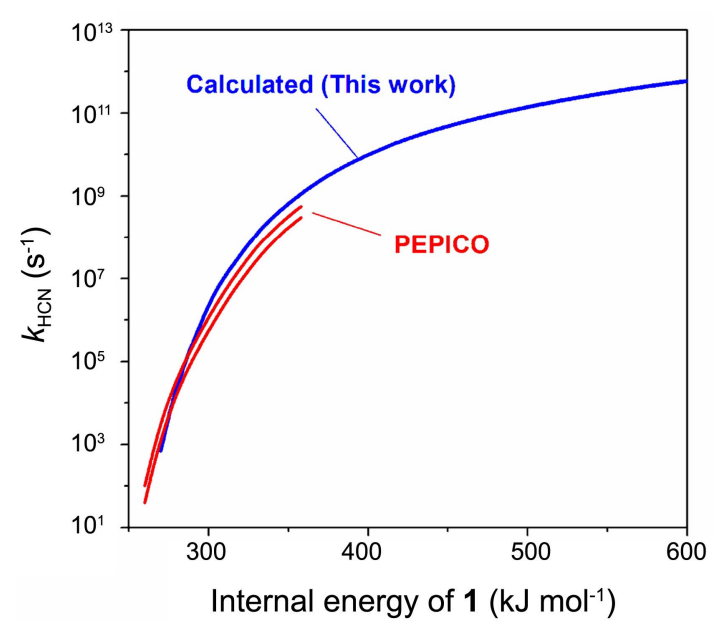

Figure 7. Theoretical and experimental energy dependences of the rate constant for the loss of $\mathrm{HCN}$ from 1 . The PEPICO data by Buff and Dannacher ${ }^{21}$ were obtained so that the experimental breakdown curves obtained at ion source residence times of 1 and $6 \mu$ s achieved best fits by calculations that used the RRKM $k_{\mathrm{HCN}}(E)$ curves and they are presented as the lower and upper lines, respectively.

frequencies for each loose TS were adjusted so that $\Delta S^{*}$ at $1000 \mathrm{~K}$ might be a certain value in a wide and reasonable range (13-46 $\left.\mathrm{J} \mathrm{mol}^{-1} \mathrm{~K}^{-1}\right){ }^{30}$ Fortunately, the variation of $\Delta S^{\star}{ }_{1000 \mathrm{~K}}$ for each dissociation step did not affect $k_{\mathrm{HCN}}$ at all, indicating that the final steps occurred much faster than the rate-limiting steps in the individual channels.

The resultant energy dependence of $k_{\mathrm{HCN}}, k_{\mathrm{HCN}}(E)$, is close to that determined by the PEPICO experiment, ${ }^{21}$ as shown in Figure 7. Buff and Dannacher obtained two breakdown curves for the dissociation of $\mathbf{1}$ with a PEPICO spectrometer with ion source residence times of 1 and $6 \mu \mathrm{s}$. The experimental breakdown curves were best-fitted by the $k_{\mathrm{HCN}}(E)$ curves calculated at $0 \mathrm{~K}$ using the RRKM formula, as shown in Figure 7. The loss of HCN was the only dissociation channel for photon energies ranging from 12.0 to $12.5 \mathrm{eV}$. To convert the (photon) energy of the $k_{\mathrm{HCN}}(E)$ curve by Buff and Dannacher into the ion internal energy, the literature ionization energy of $9.29 \mathrm{eV}^{31}$ for pyrazine was used. The ionization energy $(9.33 \mathrm{eV})$ that was calculated with the G3/ /B3LYP method was very close to the experimental value. It should be noted that because the breakdown curves were obtained for up to $12.5 \mathrm{eV}$, corresponding to $310 \mathrm{~kJ} \mathrm{~mol}^{-1}$ of internal energy of 1 , the validity of PEPICO $k_{\mathrm{HCN}}(E)$ curves higher than $310 \mathrm{~kJ} \mathrm{~mol}^{-1}$ is not guaranteed. Considering this, it is concluded that the present calculated $k_{\mathrm{HCN}}(E)$ agrees with the PEPICO result on the microsecond time scale.

The calculated relative abundances of $\mathrm{CH}_{2}=\mathrm{C}=\mathrm{N}=\mathrm{CH}^{+}$. and $\mathrm{CH}_{2}=\mathrm{N}=\mathrm{C}=\mathrm{CH}^{+}$were negligible. Their sum was less than $0.1 \%$ at the energies up to $420 \mathrm{~kJ} \mathrm{~mol}^{-1}$. As the energy increased, their abundances gradually increased. The abundances of the former and the latter were 1 and $0.1 \%$ at $600 \mathrm{~kJ} \mathrm{~mol}^{-1}$, respectively. Namely, the formation of $\mathrm{CH}=\mathrm{CHN} \equiv \mathrm{CH}^{+\bullet}$ (channel 1) was predominant, agreeing with the above prediction based on comparing the overall 
critical energies. The relative abundances of the $(E)$ - and (Z)$\mathrm{CH}=\mathrm{CHN} \equiv \mathrm{CH}^{+}$isomers could not be calculated in this work. Before the dissociations, the $\mathrm{H}$ bridged intermediates $\mathbf{3}$ and $\mathbf{4}$ are rapidly interconvertible. Therefore, the relative abundances of the $E$ and $Z$ isomers are determined mainly by the rate constants of the dissociations from a mixture of $\mathbf{3}$ and $\mathbf{4}$ to the product isomers. However, their rate constants could not be calculated with confidence because the corresponding TSs could not be located as described above. It is only predicted that the $E$ isomer would be more favored because it is more stable than the $Z$ isomer, assuming that other factors are the same.

The other possible primary dissociation of $\mathbf{1}$ is the loss of $\mathrm{H} \bullet$. By a direct $\mathrm{C}-\mathrm{H}$ bond cleavage, a cyclic $\mathrm{C}_{4} \mathrm{H}_{3} \mathrm{~N}_{2}{ }^{+}$ion is formed by the loss of $\mathrm{H} \bullet$. The endoergicity for this dissociation was calculated at the G3//B3LYP level and it was 311 $\mathrm{kJ} \mathrm{mol}^{-1}$. Comparing this to the overall critical energy (266 $\mathrm{kJ} \mathrm{mol}^{-1}$ ) of channel 1, the loss of $\mathrm{H} \bullet$ is energetically far less favored than the loss of HCN. This agrees with the experimental result that the $\mathrm{m} / \mathrm{z} 79$ peak corresponding to the $\mathrm{H} \bullet$ loss is very small in the mass spectrum ${ }^{23}$ and the collision-induced dissociation spectrum ${ }^{17}$ of pyrazine. The $\mathrm{CH}=\mathrm{CHN} \equiv \mathrm{CH}^{+\bullet}$ ion can eliminate $\mathrm{HCN}$ to form the acetylene radical cation, which is another major fragment ion in the mass spectrum of pyrazine. The endoergicity for the formation of $\mathrm{CH} \equiv \mathrm{CH}^{+\bullet}+2 \mathrm{HCN}$ from 1 calculated at the $\mathrm{G} 3 /$ /B3LYP level was $465 \mathrm{~kJ} \mathrm{~mol}^{-1}$.

\section{Conclusions}

The kinetic analysis based on the calculated PES showed that the formation of $\mathrm{CH}=\mathrm{CHN} \equiv \mathrm{CH}^{+}$was predominant in the loss of $\mathrm{HCN}$ from 1, which was thermodynamically less favored compared to the formation of $\mathrm{CH}_{2}=\mathrm{N}=\mathrm{C}=\mathrm{CH}^{+\bullet}$. The energy dependence of $k_{\mathrm{HCN}}$ agreed with the PEPICO result on the microsecond time scale. The formation of $\mathrm{CH}=\mathrm{CHN} \equiv \mathrm{CH}^{+}$occurred through three steps. After a $\mathrm{C}-\mathrm{C}$ bond cleavage to form a linear intermediate, an H-bridged intermediate was formed by a rearrangement to eliminate $\mathrm{HCN}$. The other channels that were initiated by a $1,2-\mathrm{H}$ shift were not important in the dissociation of $\mathbf{1}$, in contrast to the dissociation of the pyridine molecular ion, where a 1,2- $\mathrm{H}$ shift was an important step. The dissociation kinetics and mechanisms of the other diazine molecular ions are being examined in this laboratory.

Acknowledgments. This work was supported by the National Research Foundation of Korea Grant funded by the Korean Government (2010-0008287) and by KISTI supercomputing center through the strategic support program for supercomputing application research (KSC-2010-S00-0017). The authors thank Gee Hyung Lee for assistance in theoretical calculations.

\section{References}

1. Porter, Q. N. Mass Spectrometry of Heterocyclic Compounds, 2nd ed.; John Wiley \& Sons: New York, 1985.
2. Baer, T.; Hase, W. L. Unimolecular Reaction Dynamics: Theory and Experiments; Oxford University Press: New York, 1996.

3. Choe, J. C. Int. J. Mass Spectrom. 2004, 237, 1.

4. Choe, J. C. J. Phys. Chem. A 2006, 110, 7655.

5. Choe, J. C. Chem. Phys. Lett. 2007, 435, 39.

6. Choe, J. C. J. Phys. Chem. A 2008, 112, 6190.

7. Choe, J. C. Int. J. Mass Spectrom. 2008, 278, 50.

8. Choe, J. C. Int. J. Mass Spectrom. 2009, 286, 104.

9. Choe, J. C.; Cheong, N. R.; Park, S. M. Int. J. Mass Spectrom. 2009, 279, 25.

10. Kim, S. Y.; Choe, J. C. Int. J. Mass Spectrom. 2010, 294, 40.

11. Kim, S. Y.; Choe, J. C. Int. J. Mass Spectrom. 2010, 295, 65.

12. Kim, S. Y.; Choe, J. C. Bull. Korean Chem. Soc 2010, 31, 2589.

13. Billes, F.; Klostermann, K. ACH-Models in Chemistry 1997, 134, 199.

14. Lin, M. F.; Dyakov, Y. A.; Tseng, C. M.; Mebel, A. M.; Lin, S. H.; Lee, Y. T.; Ni, C. K. J. Chem. Phys. 2005, 123, 054309.

15. Lin, M. F.; Dyakov, Y. A.; Tseng, C. M.; Mebel, A. M.; Lin, S. H.; Lee, Y. T.; Ni, C. K. J. Chem. Phys. 2006, 124, 084303.

16. Yim, M. K.; Choe, J. C. J. Phys. Chem. A 2011, ASAP.

17. Dargel, T. K.; Koch, W.; Lavorato, D. J.; McGibbon, G. A.; Terlouw, J. K.; Schwarz, H. Int. J. Mass Spectrom. 1999, 185, 925.

18. Karapanayiotis, T.; Dimopoulos-Italiano, G.; Bowen, R. D.; Terlouw, J. K. Int. J. Mass Spectrom. 2004, 236, 1.

19. Vall-Llosera, G.; Coreno, M.; Erman, P.; Huels, M.; Jakubowska, K.; Kivimaki, A.; Rachlew, E.; Stankiewicz, M. Int. J. Mass Spectrom. 2008, 275, 55.

20. Fridh, C.; Asbrink, L.; Jonsson, B. O.; Lindholm, E. Int. J. Mass Spectrom. Ion Phys. 1972, 9, 485.

21. Buff, R.; Dannacher, J. Int. J. Mass Spectrom. Ion Processes 1984, 62,1 .

22. Amunugama, R.; Rodgers, M. T. Int. J. Mass Spectrom. 2000, $195,439$.

23. NIST Chemistry WebBook, NIST Standard Reference Database Number 69.

24. Frisch, M. J. T., G. W.; Schlegel, H. B.; Scuseria, G. E.; Robb, M. A.; Cheeseman, J. R.; Scalmani, G.; Barone, V.; Mennucci, B.; Petersson, G. A.; Nakatsuji, H.; Caricato, M.; Li, X.; Hratchian, H. P.; Izmaylov, A. F.; Bloino, J.; Zheng, G.; Sonnenberg, J. L.; Hada, M.; Ehara, M.; Toyota, K.; Fukuda, R.; Hasegawa, J.; Ishida, M.; Nakajima, T.; Honda, Y.; Kitao, O.; Nakai, H.; Vreven, T.; Montgomery, J. A., Jr.; Peralta, J. E.; Ogliaro, F.; Bearpark, M.; Heyd, J. J.; Brothers, E.; Kudin, K. N.; Staroverov, V. N.; Kobayashi, R.; Normand, J.; Raghavachari, K.; Rendell, A.; Burant, J. C.; Iyengar, S. S.; Tomasi, J.; Cossi, M.; Rega, N.; Millam, N. J.; Klene, M.; Knox, J. E.; Cross, J. B.; Bakken, V.; Adamo, C.; Jaramillo, J.; Gomperts, R.; Stratmann, R. E.; Yazyev, O.; Austin, A. J.; Cammi, R.; Pomelli, C.; Ochterski, J. W.; Martin, R. L.; Morokuma, K.; Zakrzewski, V. G.; Voth, G. A.; Salvador, P.; Dannenberg, J. J.; Dapprich, S.; Daniels, A. D.; Farkas, Ö.; Foresman, J. B.; Ortiz, J. V.; Cioslowski, J.; Fox, D. J. Gaussian 09, revision A. 02; Gaussian, Inc., Wallingford CT, 2009.

25. Baboul, A. G.; Curtiss, L. A.; Redfern, P. C. J. Chem. Phys. 1999, 110,7650

26. Beyer, T.; Swinehart, D. R. ACM Commun. 1973, 16, 379.

27. Scott, A. P.; Radom, L. J. Phys. Chem. A 1996, 100, 16502.

28. Curtiss, L. A.; Raghavachari, K.; Redfern, P. C.; Rassolov, V.; Pople, J. A. J. Chem. Phys. 1998, 109, 7764.

29. The entropy at $1000 \mathrm{~K}$ of TS cis-2 $\rightarrow$ trans-2 was $27 \mathrm{~J} \mathrm{~mol}^{-1} \mathrm{~K}^{-1}$ lower than that of TS cis-2 $\rightarrow \mathbf{3}$. The vibrational frequencies of the former were calculated at the HF/6-31G(d) level and scaled by 0.8953. According to RRKM calculations using these parameters, the rate constants for cis-2 $\rightarrow$ trans-2 were smaller than those for cis $-\mathbf{2} \rightarrow \mathbf{3}$ by more than two orders of magnitude.

30. Lifshitz, C. Adv. Mass Spectrom. 1989, 11, 713.

31. Lias, S. G.; Bartmess, J. E.; Liebman, J. F.; Holmes, J. L.; D., L. R.; Mallard, W. G. J. Phys. Chem. Ref. Data 1988, 17 (Suppl. No. 1). 